\title{
PROCESSO MIGRATÓRIO DOS GUARANI E KAIOWÁ PARA O CONTEXTO URBANO DO MUNICÍPIO DE JUTI/MS E AS FORMAS DE MOBILIDADES
}

\author{
Rosicleia Machado* \\ Rodolfo Arruda Leite de Barros **
}

RESUMO: Esta pesquisa baseia-se em uma estudo teórico-metodológico a respeito do processo migratório das famílias Guarani e Kaiowá para o contexto urbano do município de Juti, Mato Grosso do Sul (MS). A abordagem estrutural da pesquisa é de natureza qualitativa, com pesquisa bibliográfica, documental e de observações. As fontes documentais utilizadas pautam-se em documentos e dados oficiais da política de Assistência Social municipal, fontes midiáticas, sendo uma das principais o do jornal O Progresso. $O$ objetivo desta pesquisa é analisar a intervenção e sistemas adotados pelas políticas públicas nas quais motivaram a mobilidade das famílias indígenas para o contexto urbano do município de Juti/MS. Ademais, atenção será dada às formas de representação dessas famílias pelos órgãos governamentais. A abordagem privilegia o tempo presente como uma forma de captar a experiência dos grupos indígenas urbanos atendidos por essas políticas públicas. A pesquisa justifica-se por sinalizar o período em que os Guarani e Kaiowá passaram a residir na área urbana do município de Juti e as causas da mobilidade temporal que levou esses grupos de famílias aos movimentos circulares. $O$ resultado esperado objetiva demonstrar os interesses políticos que impendem o desenvolvimento das famílias indígenas na região.

\begin{abstract}
This research is based on a theoretical-methodological study about the migratory process of the Guarani and Kaiowá families to the urban context of the city of Juti, Mato Grosso do Sul (MS). The structural approach of the research is qualitative in nature, with bibliographical, documental and observational research. The documental sources used are based on official documents and data of the municipal Social Assistance policy, media sources, one of the main sources being that of the newspaper $O$ Progresso. The objective of this research is to analyze the intervention and systems adopted by public policies that motivated the mobility of indigenous families to the urban context of the city of Juti/MS. Furthermore, attention will be paid to the ways in which these families are represented by government agencies. The approach privileges the present time as a way to capture the experience of urban indigenous groups served by these public policies. The research is justified by pointing out the period in which the Guarani and Kaiowá began to reside in the urban area of the municipality of Juti and the causes of the temporal mobility that led these groups of families to circular movements. The expected result aims to demonstrate the political interests that impede the development of indigenous families in the region.
\end{abstract}

PALAVRAS-CHAVE: Políticas Públicas, Povos Indígenas, Mobilidade.

KEYWORDS: Public Policies, Indigenous Peoples, Mobility.

\section{INTRODUÇAO}

Este artigo, inicia descrevendo o processo migratório, da chegada das famílias Guarani e Kaiowá para o contexto urbano do município de Juti/MS. Para o delineamento, foram

INTERLETRAS, ISSN $N^{\circ}$ 1807-1597. V. 9, Edição número 34. Outubro, 2021/ Março de 2022- p.

Dossiê: Estudos de indigenismo, negritude e miscigenação: o (des)cobrimento, colonização e o agora(?) . 
utilizadas matérias documentais produzidas pela imprensa local a partir de fontes como o jornal O Progresso ${ }^{1}$, de 1987 a 1996, e outras fontes jornalísticas contemporâneas que retratam o processo de lutas entre os indígenas da TI Jarará (Juti/MS), contra o poder judiciário do estado de Mato Grosso do Sul. Dessa forma, foram coletados dados através de alguns impressos jornalístico, sites e informações da política de assistência social.

A mídia, para a pesquisa, representa uma categoria de atores relevantes para o processo de informações, seja de caráter positivo ou negativo para uma sociedade. É nessas condições que a pesquisa se utilizou de vários meios midiáticos para recrutar informações sobre o problema pesquisado e trazer à tona um debate sobre os aspectos que descaracterizam a condição humana do indígena em contexto urbano. Através de algumas fontes midiáticas, foi possível reproduzir informações pertinentes sobre a mobilidade das famílias Guarani e Kaiowá para o contexto urbano do município de Juti.

Com a retomada de terras, cerca da vila Juty (Caarapó/MS) em 1960, 200 indígenas da etnia Kaiowá, ocuparam as terras da Fazenda São Miguel Arcanjo, alegando que as terras pertenciam aos seus ancestrais e que naquele lugar abrigava sepulturas de alguns de seus membros. Existiam dois cemitérios comprovadamente indígenas, que foram o marco histórico para o reconhecimento da TI Jarará (O PROGRESSO, 1987).

No mesmo ano de 1960, por decisão judicial determinada pelo juiz de direito Paulo Afonso de Almeida, da comarca de Caarapó/MS, foi concedido a liminar de reintegração de posse ao proprietário Miguel Arcanjo. Diante da decisão judicial, os indígenas foram expulsos da terra e levados pela Polícia Militar até a reserva Te'ýikue (Caarapó/MS).

Devido à forma de mobilidade forçada, os indígenas foram integrados a uma área pequena de 80 hectares, no entanto, não foram bem aceitos pela outra comunidade indígena, voltando a ocupar a Fazenda São Miguel Arcanjo. Nesse trâmite, os indígenas Kaiowá contaram com o apoio de outras etnias, para a retomada da área (O PROGRESSO, 1987, p. 1).

Ao serem expulsos por várias vezes da TI Jarará e sofrer massacres e assassinatos, os indígenas Guarani e Kaiowá resistiram, entre lutas e conflitos em suas terras até a demarcação oficial que teve início em 1915. Contudo, o processo de demarcações continua sem marco temporal (O PROGRESSO, 1987).

O processo de demarcação das terras dos índios Guarani do Mato Grosso do Sul teve início no ano de 1915. Das centenas de comunidades Guarani que

\footnotetext{
${ }^{1}$ O Progresso foi o primeiro jornal diário de Mato Grosso do Sul, com edições impressas e digitais de Dourados/MS e região. Foi fundado em Ponta Porã/MS em 1920, por José dos Passos Rangel Torres, renasceu em 1951 por Weimar Gonçalves Torres e em 1997 entrou na era digital, o jornal tem a missão de traduzir ideias, comunicar mudanças e fatos sociais, culturais, políticos e entre outros.

${ }^{2} T e$ 'ýi significa gente, homem; Kue é o sufixo da palavra para designar o passado, aquilo que já foi, ou seja: o termo Te'ýikue é traduzido como aldeia antiga (GOMES, 2018).
}

INTERLETRAS, ISSN $N^{\circ}$ 1807-1597. V. 9, Edição número 34. Outubro, 2021/ Março de 2022- p.

Dossiê: Estudos de indigenismo, negritude e miscigenação: o (des)cobrimento, colonização e o agora(?) . 
existiam no começo deste século, apenas vinte e uma conseguiram sobreviver a sanha histórica pela terra. É ao longo desses setenta e dois anos (1915-1987), a União (SPI/FUNAI) não demarcou sequer a metade das aldeias Guarani remanescentes. Apenas oito reservas demarcadas, as quais compreendem os oitos postos indígenas, hoje espalhados no Centro-Sul do Estado. (TETILA, 1987, p. 5).

Para Tetila, os organizadores das demarcações das TIs idealizaram agrupar os cidadãos indígenas dentro das pequenas reservas, causando a desigualdade na proporção do território. Com o grande fluxo de famílias em pouco espaço, ocorreu a desapropriação das terras, sendo estas compartilhadas entre Estado, fazendeiros e empresários rurais. Tetila também afirmou que, em muitos casos, os fazendeiros pediam para os próprios órgãos tutelares (SPI/FUNAI) realizarem o serviço de retirada dos indígenas das reservas, serviço conhecido como “Operação Limpeza” (TETILA, 1987).

No entremeio dessa passagem histórica, algumas famílias ficaram sem direção, movimentando-se aos arredores do município de Juti/MS. A chegada das famílias Guarani e Kaiowá no contexto urbano do município de Juti/MS se deu no ano de 1987, devido aos conflitos de territórios. Foram expulsas pelo fazendeiro Miguel Subtil de Oliveira, que na época declarou ser proprietário das terras onde atualmente é localizada a TI Jarará.

Juti/MS, por ser uma vila pequena, foi emancipado em 1989, quase dois anos depois de sua fundação (1987). Com poucos recursos financeiros, apenas com duas políticas públicas implantadas (educação e saúde), as famílias indígenas não receberam nenhum amparo, alimentar e nem financeiro da administração municipal. Mantiveram-se, portanto, em situação de miséria, o que levou muitas crianças à desnutrição e consequentemente ao aumento do índice da mortalidade infantil.

Devido a mobilidade forçada, os Guarani e Kaiowá foram os pioneiros na criação da primeira periferia do município, forçados ao confinamento da condição social inferior, causada pelo efeito da ingerência das políticas indigenistas. Cerca de 300 indígenas se dividiram em blocos de 10 a 15 barracos de lona, ocupando áreas desocupadas da vila Juti, sem condições mínimas para moradia.

No contexto urbano, essas famílias estiveram em situações de risco e vulnerabilidades sociais. Muitas situações promovidas pela violência estrutural e cultural, organizadas por um sistema de ideologias de indivíduos anti-indígenas, que justificavam a violência como uma aceitação natural das situações causadas pelo próprio contexto que envolvia os sujeitos.

Os grupos indígenas mantinham as relações sociais sempre próximas, como forma de força e resistência. Porém alguns empecilhos, com a falta de recursos financeiros e sem o apoio dos órgãos indigenistas, dificultava a permanência das famílias indígenas no

INTERLETRAS, ISSN N 1807-1597. V. 9, Edição número 34. Outubro, 2021/ Março de 2022- p.

Dossiê: Estudos de indigenismo, negritude e miscigenação: o (des)cobrimento, colonização e o agora(?) . 
contexto urbano.

Entre 1996 a 1999, havia 46 famílias indígenas no contexto urbano, entre eles, crianças e adolescentes, frequentando a escola pública de Juti. As famílias contavam com a rede pública de saúde do não-indígena. Porém, os serviços ofertados pela administração não contemplavam (e não contemplam até hoje) as especificidades da cultura indígena. Em situações de alta complexidade, a rede de saúde transferia os pacientes para outras regiões (O PROGRESSO, 1996, p. 8).

Em 07 de Junho de 1996, em nota para o jornal O Progresso, alguns Guarani e Kaiowá relataram através de cartas, o seguinte comentário: "[...] 'Não podemos mais viver nas favelas', ressaltam, lembrando que estão passando fome e que são desprezados pela sociedade". Entre tantas violências, relataram que sofriam abusos por parte dos brancos e que as autoridades locais não se posicionavam em relação aos abusos (O PROGRESSO, 1996, p. 8).

Sofrendo com a falta de respeito, de alimentos e trabalho, muitas famílias voltaram a residir na TI Jarará, ficando apenas um pequeno grupo de indígenas na cidade ( $\mathrm{O}$ PROGRESSO, 1996, p. 8):

Desde 1996, em nota publicada pelo O Progresso, o Conselho Indigenista Missionário (CIMI) e a FUNAI protegiam apenas causas de indígenas aldeados. Os demais, como os que se movimentavam pela cidade devido à apropriação do Estado sobre suas terras, ficavam desassistidos tanto pelos órgãos indigenistas, como pela administração local. A falsa representação de proteção das instituições públicas e da política indigenista é um resquício da ingerência política que envolve interesses em comum entre atores políticos e servidores públicos. Os interesses interferiram na organização das ações de proteção aos grupos originários. Ações que deveriam proteger e criar oportunidades para as famílias indígenas, terminam por causar efeitos indesejáveis.

O processo de demarcação de terras indígenas em Mato Grosso do Sul ainda não foi concluído. O estado ainda é palco de dezenas de conflitos fundiários, envolvendo fazendeiros e indígenas Guarani e Kaiowá. Essa situação está relacionada com o retrocesso de algumas políticas públicas, ministradas pelo Governo Federal, que tem considerado grandes projetos agrícolas e extrativistas em terras indígenas sem a avaliação e aprovação dos indígenas. O tekoha passou a ser mercadoria na mão da cúpula governamental e os parlamentares, por sua vez, silenciam os povos indígenas e se recusam a ouvi-los.

O processo de desenvolvimento - com criações de novas empresas nas terras indígenas continua ameaçando de diversas formas os direitos dos indígenas. Com a minimização de espaços, os grupos indígenas ficam sem condições de produzir e sem alguns recursos naturais, que são utilizados para sua subsistência. Sem esses recursos, aumenta progressivamente o número de famílias indígenas pauperizadas nas cidades, uma vez que

INTERLETRAS, ISSN N 1807-1597. V. 9, Edição número 34. Outubro, 2021/ Março de 2022- p.

Dossiê: Estudos de indigenismo, negritude e miscigenação: o (des)cobrimento, colonização e o agora(?) . 
são obrigados a procurar outros meios de sobrevivência, como o trabalho formal e informal na agroindústria. Fica evidente que os anti-indígenas - os defensores da política colonial - lutam pela descaracterização dos povos originários e buscam transformá-los em trabalhadores das cidades.

Devido à expansão do monocultivo, da pecuária e da exportação de commodities, o crescimento urbano no município de Juti/MS ocasionou a expulsão de camponeses e indígenas dos seus territórios. Com a chegada desses grupos no contexto urbano, foi se agravando ainda mais o fluxo migratório e as questões econômicas da região.

Segundo estudo realizado pelo Serviço Brasileiro de Apoio às Micro e Pequenas Empresas (SEBRAE) no município de Juti/MS (2014) e considerando os dados do IBGE (2010), o processo de urbanização foi intenso nos últimos anos. O estudo aponta que $42 \%$ da população, entre indígenas e camponeses, moravam entre campo, reserva e aldeia, devido à procura por melhores condições de vida e as dificuldades de garantir a subsistência familiar causadas pela expansão do agronegócio. O número de moradores no campo caiu para $10 \%$. A migração para a cidade, por sua vez, aumentou a população urbana para mais de 65\% (SEBRAE, 2014).

Com o aumento da taxa do crescimento populacional urbano, considerando a distribuição dos domicílios por rendimento per capita, o município de Juti/MS passou a ter uma taxa de $11 \%$ de famílias sem renda alguma e nessa porcentagem se inserem as famílias Guarani e Kaiowá (IBGE 2010 apud SEBRAE 2014).

Segundo o diagnóstico socioterritorial, de 2016 a 2017 do Centro de Referência de Assistência Social (CRAS), do Município de Juti/MS, a etnografia apresentada no mapeamento mostra que atualmente sobrevivem 87 famílias indígenas Guarani e Kaiowá no contexto urbano, sendo aproximadamente 296 indivíduos entre crianças, adolescentes, jovens, adultos e idosos. O mapeamento foi realizado com ajuda de uma agente de saúde indígena Kaiowá, que conhece a realidade das famílias na área urbana. 20,7\% dessas famílias estão localizadas entre o Sul e Sudeste do município, correspondendo o maior número de indígenas concentrados na mesma área; 4,4\% estão localizados no Leste e Nordeste; e 3,5 \% estão localizados no Norte e Noroeste. Os demais indivíduos estão dispersos pelo município (MACHADO, 2017).

Em 2017, a Coordenação Regional da FUNAI de Dourados/MS realizou um Relatório de Mapeamento Qualificado de todos os casos de crianças e jovens indígenas em situação de acolhimento institucional e familiar da região. Através da análise situacional, foram identificadas apenas 83 famílias em contexto urbano no município de Juti, ou seja, quatro famílias a menos que o Diagnóstico Socioterritorial da unidade CRAS. Isso significa que esses números são variantes e essas famílias são pertencentes aos movimentos circulares e temporais.

INTERLETRAS, ISSN N 1807-1597. V. 9, Edição número 34. Outubro, 2021/ Março de 2022- p.

Dossiê: Estudos de indigenismo, negritude e miscigenação: o (des)cobrimento, colonização e o agora(?) . 


\section{ORGANIZAÇÃO ESPACIAL}

Cerca de $10 \%$ dos moradores indígenas em contexto urbano possuem residências fixas; $40 \%$ pertencem aos movimentos circulares, ou seja, movimentam-se pela cidade, trocando de residências regularmente; e $50 \%$ fazem parte do movimento temporário, permanecem por um tempo na cidade e depois voltam a residir na aldeia (MACHADO, 2017). Também existem aqueles que possuem residências na cidade e na aldeia ao mesmo tempo, como estratégia de sobrevivência. De acordo com a mobilidade temporal, circulando entre cidade e aldeia, esse processo se dá devido às condições socioeconômicas do grupo. Por se tratarem de famílias que fazem parte do meu convívio profissional, percebo que a organização espacial desses grupos é definida por fatores políticos, econômicos, sociais e culturais.

Cada espaço escolhido pelas famílias indígenas passa a ter suas funcionalidades específicas, definindo suas significações sociais e funcionalidades, assim como a dimensão espacial ocupada por esses grupos, que constituíram resistências nesses espaços e passaram a criar identidades territoriais próprias. As condições econômicas das famílias indígenas em contexto urbano estão relacionadas com a falta de trabalho, o que promoveria a subsistência familiar com a coesão política que alimenta as perspectivas de desenvolvimento desses grupos indígenas.

A situação espacial de cada família está associada ao poder aquisitivo do grupo, pois são os meios de mobilidades que definem apropriação do espaço escolhido na área pretendida para habitar. Para compreender como essas famílias Guarani e Kaiowá passaram a residir no contexto urbano, foi preciso analisar o processo de mobilidade cotidiano desses indivíduos, observando as diferentes organizações sociais.

O andamento da análise inicia com dados e informações da política de Assistência Social do município de Juti, que possibilitou adentrar em uma história de desafios e incertezas, pois ainda não existe uma legislação específica de assistência que possa amparar as famílias indígenas fora das aldeias. Como sustentabilidade das informações, foi utilizado a Constituição Federal de 1988, um guia de direitos para garantir o reconhecimento à organização social, costumes, línguas, crenças e tradições já reconhecidos. De acordo com o Artigo 231, o texto não deixa claro sobre a distinção de direitos enquanto mobilidade/organização espacial na aldeia ou contexto urbano.

Ao se engajar nessa brecha, para fins de complementar o estudo, utilizo de situações vivenciadas ao longo dos oito anos de profissão enquanto Assistente Social da unidade CRAS de Juti/MS. Por várias vezes me deparei com violações de direitos envolvendo indígenas em circunstâncias políticas, econômicas, sociais e culturais para fins particulares.

Conforme alguns dados apontados por registros municipal, emitidos pela política de assistência social, ficaram mais evidentes as diferenciações das formas de mobilidade dos

INTERLETRAS, ISSN N 1807-1597. V. 9, Edição número 34. Outubro, 2021/ Março de 2022- p.

Dossiê: Estudos de indigenismo, negritude e miscigenação: o (des)cobrimento, colonização e o agora(?) . 
Guarani e Kaiowá. Em um primeiro momento houve formas de mobilidade e de remoções forçadas, onde os indígenas tiveram que deixar seu território devido às pressões e violências sofridas. É uma característica da forma de imobilidade derivada do processo colonial, que forçou os índios ao confinamento. Até hoje, os povos indígenas lutam para mudar o sentido da história indígena. Há a permanência de uma forma de prática de imobilidade controlada ainda pela ideologia tutelar.

É importante ressaltar que a mobilidade tradicional dos indígenas na retomada Taquara e na aldeia Jarará, foi transformada em nova forma de mobilidade negativa para as famílias indígenas. Isso ocorreu devido aos impactos da Companhia Matte Laranjeiras e outras explorações do agronegócio, como o plantio da cana-de-açúcar e do crescimento da agropecuária, ocorridas na região. Os movimentos circulares - cidade x aldeia e ou vice-versa - são formas de representar a mobilidade forçada (negativa), pois os índios ainda sobrevivem sobre pressões e ameaças pelo crescimento do Agro e posições governamentais.

Com a redução dos territórios, se inviabiliza o retorno de muitas famílias indígenas para as terras tradicionais. Outro fator que também dificulta essa ação, são as novas formas de organização política dentro dos pequenos espaços na aldeia, ou seja: os conflitos por disputa de liderança interferem na rede de relações sociais dos grupos. Por outro lado, essa redução de espaço implica em outros problemas públicos: 1) na economia familiar, sem os meios naturais para a subsistência - caça e pesca; 2) na política de educação e saúde indígena que se encontra em péssimas condições; 3) e por fim, o esparramo - uma mobilidade negativa, também conhecida pelos indígenas como Sarambi: "um momento histórico de 'desordem' em que os parentes foram esparramados e promoveu a fragmentação forçada das tey ${ }^{\prime} i^{3}$ que antes viviam organizadas a partir de uma lógica própria de socialidade" (CRESPE, 2015, p. 323).

De acordo com Crespe (2015), a Changa ${ }^{4}$, categoria indígena, é outra forma de mobilidade negativa que retira os homens de perto dos grupos familiares para trabalhos em fazendas e outras regiões, podendo durar meses. É referida como uma grande desordem para a economia doméstica kaiowá. Esse comentário explica o porquê de muitas famílias indígenas residirem nos meios urbanos e praticarem apenas mobilidades urbanas.

Para Crespe (2015), a mobilidade pode ser motivada por vários fatores que compõem uma rede de relações sociais promovidas pela circulação dentro das aldeias, pela visita da parentela, pela caça e pesca, como também "motivada pelos casamentos, festas e rituais religiosos, que possibilitavam as relações de trocas que produzia a sensação de grupo, de comunidade, como muitas vezes eles fazem referência até hoje" (CRESPE, 2015, p. 309).

\footnotetext{
${ }^{3}$ Segundo Crespe (2015, p.309), "parentela formada por dezena de famílias nucleares reunidas em torno de um chefe de parentela, o hi'u - chefe de uma parentela".

${ }^{4}$ Trabalhos em fazendas e outras regiões.
}

INTERLETRAS, ISSN N 1807-1597. V. 9, Edição número 34. Outubro, 2021/ Março de 2022- p.

Dossiê: Estudos de indigenismo, negritude e miscigenação: o (des)cobrimento, colonização e o agora(?) . 
Essa mobilidade também está relacionada com a criação do município de Juti em 1989, quando a vila Juti deixou de ser distrito de Caarapó e passou a ser município de Juti/MS. Neste momento, foi realizada a primeira eleição para prefeito. Com 1452 votos, venceu José Adolar de Castro Filho, conhecido por "Dolinha" (PFL). Ao tomar posse, em 1989, José Adolar de Castro Filho realizou doações de terrenos às famílias indígenas para que o município fosse povoado rapidamente. Outro fator muito comum nos relatos dos indígenas em contexto urbano - com os quais tenho contato diariamente - é a falta de oportunidades de inserção no mercado de trabalho. Tal situação os leva aos movimentos temporais.

Conhecer a trajetória desses grupos, entre os diferentes segmentos de organizações sociais e políticos, nos permite delinear melhor o modo de pertencimento do local onde vivem, como a construção da identidade sobre o novo espaço social. A resiliência sobre os fatores negativos da mobilidade - que os levaram para o novo espaço - são os pressupostos que nos orientam a entender o sentido e o sentimento de pertencimento local.

Todavia, a capacidade transformativa dos Guarani e Kaiowá no contexto urbano retoma a ideia de flexibilidade e superação, como qualquer outro sujeito que incessantemente busca nesse universo de armadilhas pela adaptação. Sem dúvidas, os Guarani e Kaiowá vêm superando esses obstáculos sociais e políticos e conquistando seu espaço nos mais diversos contextos. Ainda que lentamente e em um cenário conflituoso, esses grupos permanecem resistentes.

A abordagem etnográfica utilizada na pesquisa permite aos leitores uma análise mais detalhada sobre o processo de organização dos Guarani e Kaiowá e a construção da identidade sobre o novo espaço de pertencimento. Esses espaços resultam em processos de diferenciações sociais da forma que os sujeitos se comportam no espaço.

Para Bourdieu (1989), esse espaço é chamado de campo, onde os sujeitos se relacionam e criam seu próprio objeto artístico, social, político e educacional. É nesse espaço estruturado que podemos analisar as características de seus ocupantes dentro da história. O campo é delimitado por uma estrutura de forças e de lutas, onde cada sujeito atua conforme sua posição no espaço, seja conservando sua estrutura, sua cultura ou a modificando para outras.

Dessa forma, a escolha espacial das famílias Guarani e Kaiowá em contexto urbano sempre ocorre em locais segregados socioespacialmente devido a suas condições socioeconômicas e seus costumes culturais. A maioria das famílias mora nas extremidades da cidade, em bairros mais isolados ou em terrenos abandonados. Algumas áreas são pequenas, sem condições para o cultivo de plantas, hortaliças, entre outros alimentos.

Ao se sentirem parte da contextura da comunidade de pertencimento, os Guarani e

INTERLETRAS, ISSN N $N^{\circ}$ 1807-1597. V. 9, Edição número 34. Outubro, 2021/ Março de 2022- p.

Dossiê: Estudos de indigenismo, negritude e miscigenação: o (des)cobrimento, colonização e o agora(?) . 
Kaiowá passam a produzir elementos epistemológicos evidenciados por suas características da singularidade cultural, e criam as primeiras redes de relações sociais com os vizinhos mais próximos.

Porém, o isolamento de alguns indivíduos no contexto urbano, favorece $o$ desconhecimento do que se constitui como cidade. Essa relação está ligada aos percursos dos movimentos/mobilidades circulares, que podem ser sempre nos mesmos lugares, sendo cidade $\mathrm{x}$ aldeia ou vice-versa. Nessas condições, se manifestam os interesses políticos assistencialistas, que diferenciam suas ações conforme suas necessidades de poder entre promessas contraditórias e prestação de serviços momentâneos.

Viver na cidade é um direito de todos. Porém, é necessário conhecer a diversidade na sua pluralidade para que seja possível atender os indivíduos que nela se compõem. Os diversos segmentos sociais precisam ser representados por servidores públicos capazes de agir pelo coletivo.

Não podemos afirmar que os indígenas migram para a cidade atraídos apenas pelas "maravilhas" do contexto urbano. Tal afirmação vai além da simples atração do fetichismo. Hoje, essa migração, está mais relacionada com a expansão do agronegócio e a exportação do capital nos territórios indígenas, que tem provocado desordem política. Estes fatores são mais precisos do que a ideia das atrações da cidade, visto que essa desordem tem provocado a evasão de mais grupos para a cidade.

Para os anti-indígenas, é difícil a compreensão da ressignificação da cultura indígena dentro do contexto urbano, mesmo deixando de lado algumas práticas culturais para exercer a do não-indígena. Essa ressignificação dos hábitos culturais é caracterizada como um direito, segundo a Constituição Federal de 1988.

\section{DINÂMICA FAMILIAR}

Falar em dinâmica familiar indígena em contexto urbano requer uma atenção integral, porque suas características estão fortemente relacionadas com seus modus vivendi culturais. As relações sociais entre os Guarani e Kaiowá são fortemente ligadas e marcadas pelos vínculos religiosos, culturais, políticos e afetivos criados durante a convivência em grupos, seja familiar, de parentela ou de amizades externas.

Através dessa análise, foi possível identificar que os Guarani e Kaiowá, em contexto urbano do município de Juti, enquadram-se em dois tipos de famílias, a "Família Extensa" ${ }^{5}$ que apresenta mais de duas gerações convivendo na mesma casa; e a "Família

\footnotetext{
${ }^{5}$ Família Extensa: grupos macro familiares que detêm formas de organização da ocupação espacial dentro dos tekoha determinada por relações de afinidade e consanguinidade. É composta pelo casal, filhos, genros, netos, irmãos e constitui uma unidade de produção e consumo. (ISA, 2012).
}

INTERLETRAS, ISSN N 1807-1597. V. 9, Edição número 34. Outubro, 2021/ Março de 2022- p.

Dossiê: Estudos de indigenismo, negritude e miscigenação: o (des)cobrimento, colonização e o agora(?) . 
Nuclear Ampliada", ${ }^{6}$ que possui no mesmo ambiente membros adicionais, amigos, tios, irmãos, primos, avós e entre outros. Esses termos são utilizados por antropólogos e profissionais responsáveis por estudar o homem e suas interações com a sociedade. Sendo assim, a definição familiar dos indígenas em contexto urbano do município está relacionada com as características e os aspectos da composição e grau de parentesco dos membros que compõem o grupo familiar.

De acordo com Pereira (2016), a ligação da parentela com outros campos de vida social não caracteriza só o modelo ideal, lógico ou estrutural, também insere uma compreensão presumível dos mecanismos institucionais, onde cada indivíduo ocupa posições distintas em suas relações sociais. Dessa forma, essa relação está ligada com o Che Ypyky Kuera, que significa o fogo doméstico - termo utilizado pelos Guarani que refere ao grupo de parentela mais próximo. O fogo doméstico 'é uma pré-condição para a existência humana na sociedade Kaiowá', simboliza o agrupamento da família, a convivência íntima e contínua (PEREIRA, 2016, p. 37).

O fogo doméstico é muito presente nas relações sociais dos Guarani e Kaiowá em contexto urbano, apenas os mais velhos compreendem a força atrativa e o significado do fogo para as relações consanguíneas. Para a geração mais nova, principalmente aqueles indivíduos que conviveram pouco com o grupo no tekoha, o fogo é visto apenas como um meio de produzir alimentos. Devido ao distanciamento da existência social, o pertencimento ao fogo doméstico se torna secundário ao novo modelo organizacional existente no meio urbano, de modo que, o plano ideológico existente entre esses grupos evidencia a distinção de estilos atribuídos por cada família, estilos que modificam cada vez mais com a morfologia social da convivência no meio urbano.

Para os Guarani e Kaiowá, em contexto urbano, a liderança da família ainda está sobre a responsabilidade do homem, do chefe da família. O líder aglutina os homens que pertencem o ambiente para que todos possam contribuir no sustento do lar. É comum observar entre as famílias a divisão social do trabalho. As funções econômicas na dinâmica cotidiana desse grupo são de responsabilidades do líder da casa; as tarefas de casa e dos filhos ficam aos cuidados das mulheres.

Por considerar que a maioria das famílias indígenas, em contexto urbano do município de Juti/MS, estão divididas entre famílias extensas e nucleares ampliadas, a área de convivência dessas famílias é caracterizada por uma casa centralizada, onde reside o chefe da família (pais) e ao redor da casa principal, movimentam-se e sobrevivem o restante da família. A cozinha é sempre separada dos demais ambientes e todos cozinham e se alimentam no mesmo espaço, mesmo aqueles que moram em casas de alvenaria ou madeira possuem um barraco de lona como sua cozinha.

\footnotetext{
${ }^{6}$ Família Nuclear Ampliada: É aquela composta de um homem e uma mulher que coabitam e mantêm um relacionamento sexual socialmente aprovado, tendo pelo menos um filho, porem possui no mesmo ambiente, outros membros adicionais, podendo ser parentes e amigos (ISA, 2014).
}

INTERLETRAS, ISSN N 1807-1597. V. 9, Edição número 34. Outubro, 2021/ Março de 2022- p.

Dossiê: Estudos de indigenismo, negritude e miscigenação: o (des)cobrimento, colonização e o agora(?) . 
Quando entra algum tipo de renda no ambiente familiar, seja proveniente do trabalho na roça ou de programas sociais como o Bolsa Família e Vale Renda, são destinados em primeiro lugar para a compra de alimentos. É comum notar que as famílias se reúnem e comemoram todos juntos - a confraternização e a divisão de alimentos são bastante comuns na cultura Guarani e Kaiowá, reforçando os vínculos afetivos.

Os Guarani e Kaiowá possuem um sistema social aberto entre sua comunidade em constante interação com o meio natural e cultural - transitam facilmente pelas aldeias e região. Já considerando a circulação no contexto urbano, ainda é possível observar o distanciamento que a sociedade não-indígena mantém em relação ao indígena em contexto urbano e rural. O sistema social não é completamente aberto.

Em análise e observações, ao visitar unidades públicas e comerciais, tive a oportunidade de avaliar como esses grupos se comportam na sociedade e como eles lidam com a superação da discriminação, marcada pela falta de protagonismo, pelo risco social e vulnerabilidades. Para superar as limitações impostas por determinados grupos sociais, observei que os Guarani e Kaiowá, em contexto urbano, se submetem ao enquadramento social e político, sem discordar com as regras estabelecidas.

Mills (1969) aponta que o poder de visualizar, ou seja, observar a sociedade como um todo, é o elemento fundamental da imaginação que permite compreender o sentido de perspectiva das experiências pessoais e das preconcepções culturais. Ao conhecer o diferente é possível construir instrumentos operacionais que venham garantir o acesso às políticas públicas diferenciadas.

O estudo e as observações demonstram as fragilidades das políticas públicas, que apresentam razoável capacidade de liderança política e disciplina democrática por parte da administração pública. As ações adotadas pelos sucessivos governos em relação às políticas públicas sempre foram o maior problema para o andamento dessas políticas.

\section{DESEMPREGO E RENDA}

Por se tratar de um município de porte pequeno, aproximadamente 6.638 habitantes, a maior fonte de renda e trabalho de Juti está concentrada na agropecuária, com $49 \%$ do Produto Interno Bruto (PIB) municipal. O comércio local concentra 39\% o serviço público $37 \%$. Visto que as vagas de trabalhos são limitadas e não atendem toda a demanda de trabalhadores, uma grande parte permanece fora do mercado de trabalho. Entre os desempregados estão os indígenas, os trabalhadores sem escolaridade, os que ultrapassam os 50 anos de idade e os que não possuem qualificação profissional (SEBRAE, 2014).

Desde 1999, o agronegócio é o que mais contribuí com PIB municipal, porém, não significa que aumentaram as vagas de trabalho, mas sim, a supremacia do capital financeiro sobre o capital produzido pela exploração das terras. Apesar desse crescimento de bens de consumo gerado pelo capital, o município não dispõe de políticas públicas que apoiam a geração de emprego e de renda e que fiscalizem a exploração do trabalho

INTERLETRAS, ISSN N 1807-1597. V. 9, Edição número 34. Outubro, 2021/ Março de 2022- p.

Dossiê: Estudos de indigenismo, negritude e miscigenação: o (des)cobrimento, colonização e o agora(?) . 
indígena e dos demais segmentos sociais, de modo que atenda respeitosamente aos indivíduos.

É nesse sistema de carência de políticas públicas de emprego e renda que as famílias indígenas em contexto urbano estão inseridas. A precarização, a falta de vagas no mercado de trabalho e a insuficiência de renda aumentam a proporção de trabalhadores e famílias em condições de extrema pobreza. Sem espaço e sem condições financeiras para a concentração do cultivo, esses grupos tendem cada vez mais a mudar os padrões de vida.

Esse cenário negativo aumenta também a procura por benefícios sociais e programas de transferências de renda. Só o Programa Bolsa Família atende 852 famílias beneficiadas, equivalente a $36,14 \%$ da população do município, considerando que a maioria das famílias indígenas do contexto urbano sobrevivem desses programas sociais (SIGPBF, 2019).

$\mathrm{Na}$ cidade, a principal atividade de renda para os indígenas está relacionada com o trabalho na roça de mandioca. Embora seja uma das opções de trabalho que mais emprega indígenas, a superexploração da força de trabalho indígena vem se alastrando cada vez mais, seja nas plantações - não só de mandioca, mas também de plantações frutíferas em outros estados.

A falta de emprego não só afeta as condições alimentares como também a organização familiar. O desemprego tem aumentado o uso de bebidas alcóolicas, os atos infracionais, a violência doméstica e outras violências.

Considerando o aumento da produção do agronegócio, outra oportunidade de trabalho para os indígenas surge com a produção da cana de açúcar. O site Amambai Notícias (2016) afirma que o os índios são mão de obra predominante nas usinas.

De acordo com essa visão, o trabalho, ao mesmo tempo que estrutura a relação das redes sociais, permite a satisfação das necessidades dos indivíduos e cria identidades, além de dar significado à vida. Enfrentar os paradoxos organizacionais do mercado de trabalho não é tarefa fácil, ainda mais porque a cultura Guarani e Kaiowá mantém o conceito próprio do trabalho tradicional.

\section{CONIDERAÇOES FINAIS}

O descompasso da política pública territorial, que levou as famílias Guarani e Kaiowá para o contexto urbano do município de Juti/MS, incide em sucessivas mudanças na história dos Guarani e Kaiowá. Algumas famílias sobreviveram ao longo processo violento da década de 60, quando foram expulsas pela primeira vez de suas terras, conhecidas hoje como aldeia Jarara.

INTERLETRAS, ISSN N 1807-1597. V. 9, Edição número 34. Outubro, 2021/ Março de 2022- p.

Dossiê: Estudos de indigenismo, negritude e miscigenação: o (des)cobrimento, colonização e o agora(?). 
Algumas famílias permaneceram fortes na luta por seus territórios, outras se deslocaram para fazendas vizinhas às margens de rodovias, e até mesmo passaram a viver em outras TIs e Reservas da região. Aos poucos, uma nova configuração de mobilidade espacial foi surgindo, configurada pela ocupação territorial no contexto urbano do município de Juti/MS. Em meio a essa movimentação, o trânsito entre aldeia e cidade tornou-se comum entre os Guarani e Kaiowá. As movimentações se dão em função das amplitudes das relações de parentelas, da comercialização de produtos e de estratégias de sobrevivência, decorrentes da falta de espaço territorial.

Com a falta de terra e a evasão das aldeias, os Guarani e Kaiowá em contexto urbano passaram a definir suas organizações culturais por situações paradoxais. Por um lado, tiveram de se adaptar ao modo de vida do não-indígena; por outro, manter vivo o valor étnico cultural dentro de uma cultura opressora.

Dessa forma, podemos concluir que o Estado tenta concentrar todo o seu esforço na promoção de sociedade pacífica e inclusiva para um sistema não democrático. Porém, ainda existem questões que não foram resolvidas e dívidas pendentes, que interferem no sistema de controle social do governo. É nessa perspectiva que se justifica a falta de compreensão da sociedade e da governança sobre a permanência das famílias indígenas no contexto urbano do município de Juti/MS e o verdadeiro significado de políticas públicas para os grupos indígenas e seus direitos constitucionais.

\section{REFERÊNCIAS}

AMAMBAI NOTÍCIAS. O Trabalho Indígena na Usina Nova América, em Caarapó. Disponível em: <www.amambainoticias.com.br/cidades/o-trabalho-indigena-na-usinanova-america-em-caarapo>. Acesso em: 08 set. 2019.

BOURDIEU, Pierre. O poder simbólico. Rio de Janeiro: Bertrand Brasil S.A, 1989.

BRASIL. [Constituição (1988)]. Constituição da República Federativa do Brasil: Texto Constitucional promulgado em 5 de outubro de 1988, com as alterações adotadas pelas emendas Constitucionais $n^{\circ} 1 / 92$ a 67/2010, pelo Decreto $n^{\circ} 186 / 2008$ e pelas Emendas Constitucionais de Revisão $\mathrm{n}^{\circ} 1$ a 6/94. Brasília, DF: Senado Federal, Subsecretaria de Edições Técnicas, [2011]. 578 p.

. Ministério do Desenvolvimento Social. Sistema de Gestão do Programa Bolsa Família (SIGPBF). Brasília, DF: 20 de Agosto de 2019. Disponível em: <http://www.mds.gov.br/mds-sigpbf-web/indexPublico.jsf/>. Acesso em: 20 ago. 2019.

CRESPE, Aline Castilho. Mobilidade e temporalidade Kaiowá: do tekoha à reserva, do tekoharã ao tekoha. Tese (Doutorado em História) - Faculdade de Ciências Humanas,

INTERLETRAS, ISSN N 1807-1597. V. 9, Edição número 34. Outubro, 2021/ Março de 2022- p.

Dossiê: Estudos de indigenismo, negritude e miscigenação: o (des)cobrimento, colonização e o agora(?) . 
Universidade Federal da Grande Dourados (UFGD), 2015.

FUNDAÇÃO NACIONAL DO ÍNDIO. Mapeamento qualificado de todos os casos de Crianças e Jovens Indígenas em Situação de Acolhimento Institucional e Familiar da Região de Dourados/ MS. Coordenação Regional da Funai de Dourados/MS. Serviço de Promoção dos Direitos Sociais e de Cidadania (SEDISC), Novembro de 2017.

MACHADO, Rosicleia. Diagnóstico socioterritorial do centro de referência de assistência social - CRAS (Urbano e Rural). Prefeitura Municipal de Juti/MS, 2017. Disponível em: <http://www.juti.ms.gov.br/wpcontent/uploads/2019/04/DIAGN\%C3\%93STICO-S\%C3\%93CIO-TERRITORIAISDO-CRAS-URBANO-E-CRAS-RURAL-JUTI-MS-2.pdf>. Acesso em: 20 jan. 2020.

MILLS, Wright C. A imaginação sociológica. $2^{\text {a }}$ Edição. Rio de Janeiro: Zahar Editores, 1969. $246 \mathrm{p}$

O PROGRESSO. Aldeia Jarará é reocupada por causa da fome e do desemprego: Cerca de 300 índios Caiuá-Guarani moram em barracas de lona, na periferia da cidade, desde que foram expulsos da Reserva. Dourados, 25 mar. 1996, p. 08.

Caiuás retornam à Jarara e têm apoio dos Terenas. Dourados, 27 fev. 1987, p. 1.

Índios são despejados de fazenda (de novo). Dourados, 15 mai. 1987. p. 3.

Kaiowá e Guarani pedem apoio a entidades: Eles precisam de alimentos pelo menos até a colheita da primeira safra, cujo plantio já foi iniciado. Dourados, 07 jun. 1996. p. 3.

Tensão marca o terceiro dia de ocupação da Aldeia Jarará.

Dourados, 26 mar. 1996, p. 8.

PEREIRA, Levi. Marques. A criança kaiowa, o fogo doméstico e o mundo dos parentes: espaços de sociabilidade. In: $32^{\circ}$ Encontro Anual da Anpocs, 2008, Caxambu. $\begin{array}{llll}32^{\circ} & \text { Encontro Anual da Anpocs, } & 2008 .\end{array}$

Expropriação dos territórios kaiowá e guarani: implicações nos processos de reprodução social e sentidos atribuídos às ações para reaver territórios - tekoharã. Revista de Antropologia da UFSCar, v. 4, n. 2, jul./dez. 2012, p.124-133.

PEREIRA, Sílvia Regina. Percursos urbanos: mobilidade espacial, acessibilidade e o direito à cidade. Diez años de cambios en el Mundo, en la Geografía y en las Ciencias Sociales, 1999-2008. Actas del X Coloquio Internacional de Geocrítica, Universidad de Barcelona, 26-30 mai. 2008.

INTERLETRAS, ISSN N 1807-1597. V. 9, Edição número 34. Outubro, 2021/ Março de 2022- p.

Dossiê: Estudos de indigenismo, negritude e miscigenação: o (des)cobrimento, colonização e o agora(?) . 
PREFEITURA MUNICIPAL DE JUTI/MS. Lei Orgânica Municipal de Juti-MS. Disponível em: < http:// http://www.juti.ms.gov.br/2019/02/27/lei-organica-municipalde-juti-ms//>. Acesso em: 04 fev. 2020.

SEBRAE. Desenvolvimento Econômico Territorial/Juti Centro Sul. Disponível em: $<$ https://m.sebrae.com.br/Sebrae/Portal\%20Sebrae/UFs/MS/Anexos/Mapa\%20Oportuni dades/Livreto_JUTI.pdf>. Acesso em: 28 mar. 2019

TETILA, José Laerte Cecílio. Parem de massacrar os nossos índios guaranis. In: O Progresso. Dourados-MS, 19 de maio de 1987. p. 5.

* Graduada em Serviço Social pela Universidade Norte do Paraná (2010), mestra em Sociologia pela Universidade Federal da Grande Dourados (2020). Na linha de pesquisa: Cidadania, diversidade e movimentos sociais, sobre o projeto de pesquisa: Representações sociais sobre cidadania, democracia, violência e direitos humanos na região de fronteira: desmonte democrático, ataques aos direitos humanos e formas de resistência política. Pós-graduada em Cultura e Histórias dos povos Indígenas, sobre a área de concentração de Antropologia, pela UFMS. Atualmente, cursando uma pós-graduação em políticas públicas e projetos sociais. Tem experiência na área de Serviço Social, com ênfase na política de assistência social. https://orcid.org/0000-0002-3172-1551. http://lattes.cnpq.br/4514038931740029

**Coordenador no Programa de Pós-graduação em Sociologia (PPGS - UFGD) e Professor Adjunto na Universidade Federal da Grande Dourados - UFGD no curso de graduação em Ciências Sociais (FCH UFGD). É Mestre (2007) e Doutor (2012) em Ciências Sociais pela Universidade Estadual Paulista (UNESP), tendo feito a graduação em Filosofia (UNESP) e em Direito (UNIVEM). É membro pesquisador do LADIF (Laboratório Interdisciplinar de estudos sobre Direitos, Diversidade e Diferenças na Fronteira) atuando nas áreas da Sociologia da Violência e da Punição, Teoria Social Contemporânea e Educação em Direitos Humanos. https://orcid.org/0000-0003-3594-6907

INTERLETRAS, ISSN N 1807-1597. V. 9, Edição número 34. Outubro, 2021/ Março de 2022- p.

Dossiê: Estudos de indigenismo, negritude e miscigenação: o (des)cobrimento, colonização e o agora(?) . 